\title{
GLOBAL POSITIONING AND BRAKING SYSTEM
}

\author{
Vivek Murthy ${ }^{1}$, Srisumanithi Pandiaraj ${ }^{2}$ \\ ${ }^{I}$ Scholar, Department of Mechanical Engineering, Sri Krishna College of Technology, Coimbatore, Tamilnadu, India \\ ${ }^{2}$ Scholar, Department of Mechanical Engineering, Sri Krishna College of Technology, Coimbatore, Tamilnadu, India
}

\begin{abstract}
Over 1,46,000 people were killed in road accident in India in 2015 alone. To reduce road accidents, government is keep on implementing rules and speed regulations. To control the top speed of commercial vehicles, government installs a device termed Speed Limiting Governors. Various Researches and development are done each and every day to ensure road safety. To Ensure road safety a system termed "Global Positioning and Braking System (GPBS)" can be used. The ultimate aim of this system is to control the speed of the vehicle under different conditions. Global Positioning and Braking System is integrated with the Electronic Control Unit (ECU) of the vehicle. ECU and GPBS senses the position and angle at which the vehicle traveling with the help of onboard devices. This Global Positioning and Braking System provides an interface between the satellite and ECU. Onboard devices consists of Positioning chip and Clinometers. Positioning chip interacts with the satellite and sends the position of vehicle to GPBS. Clinometers incorporated with spirit level is used to sense the tapering angle of the steep at which the vehicle currently travels. All data from onboard devices is transmitted to Electronic Control Unit through Global Positioning and Braking System. Electronic Control Unit controls the Braking system and Fuel injector based on the received data with the help of preset program in it. Braking system is used to gradually reduce the speed of vehicle. Control over Fuel injector is done to control the power output of the engine. In a automotive, the power output is directly proportional to the speed of the vehicle. This entire system can replace Speed limiting governors which is currently used in commercial vehicles alone. GPBS can be used in all types of automotives. This system greatly ensures the road safety and reduces the road accident to greater extent.
\end{abstract}

Keywords: Braking Unit, ECU, Fuel Injector, Position, Road Safety, Speed.

\section{INTRODUCTION}

Global Positioning and Braking System controls the speed of the vehicle by actuating fuel injectors and Hydraulic modulator unit. This ECU controlled actuation is based on the location of the vehicle.

\subsection{History}

Roadways is considered to be one of the best modes of transport. Roadway's history starts from the invention of wooden wheel in Stone Age and extends till production of most luxurious vehicles. Roadways provide an easy access within and around the countries.

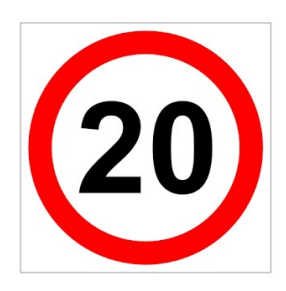

Fig 1. Speed Limit Board

\subsection{Road Accidents}

If we consider in India,second largest populated country in the world,over 1,37,000 people were killed in 2013 in road accidents which has beenincreased about 1,46,000 by 2015 . This percentage of road accidents goes on increasing year by year. Government has taken serious steps to decrease the number of road accidents. About $90 \%$ of Road accidents is only because of overspeeding. Government has instructed to use governors to over come this offense.

\subsection{GPBS}

This is very simplest system that can be used to control the speed of the vehicle. This system incorporates with a spirit level fixed clinometers. This system can be used to track the position of the vehicle based on Global Positioning System (GPS). This System along with vehicle's ECU can ensure the road safety and can replace various sensors and governors.

\subsection{What is an ECU?}

An Electronic Control Unit (ECU) is an embedded electronic device,basically a micro-computer,that senses the data from the various sensors and based on the data controls the various units of Vehicles. All electronic parts of a vehicle comes under the control of ECU.

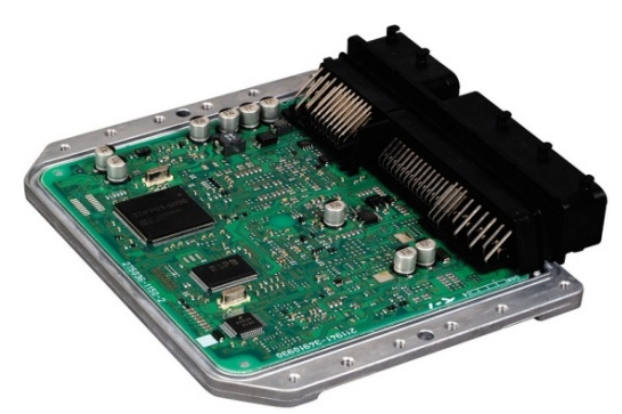

Fig 2. Typical ECU 


\section{BRAKING SYSTEM}

\subsection{Braking Unit}

A Braking unit in a Vehicle is used to apply brake to get control over the vehicle. This Braking unit converts the kinetic energy of the vehicle into heat energy. The conversion of kinetic energy to heat energy is due to Friction.

\subsection{Types of Braking System}

There are different types of braking system,

- Mechanical Braking

- Hydraulic Braking

- Air Brakes

- Vacuum Braking

- Electronic Braking

Hydraulic Braking system is most commonly used braking system in vehicles since it is highly efficient. Air brakes are used only in some heavy load applications.

\subsection{Hydraulic Braking System}

In Hydraulic system, an incompressible fluid is used to apply brakes to wheel hubs. This Braking system works on the principle of Pascal's law.

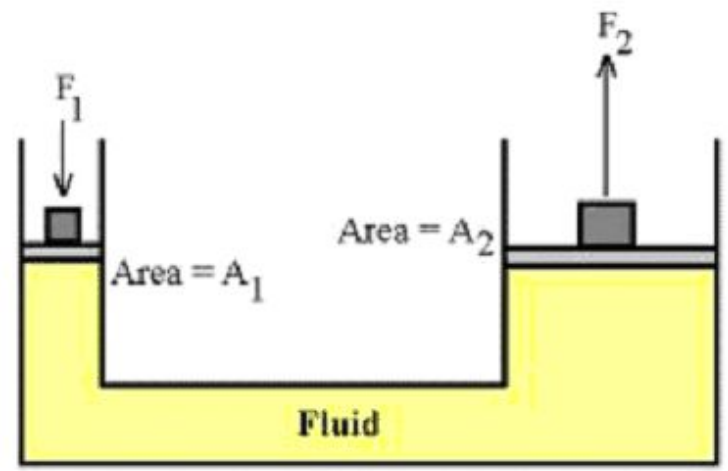

Fig 3. Working of Pascal's law

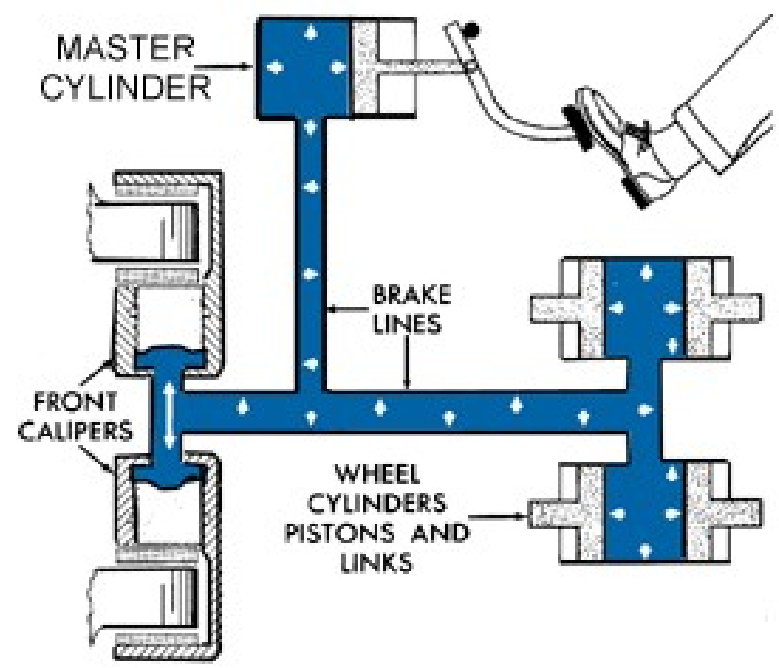

Fig 4. Application of Pascal's law in Hydraulic braking
This Hydraulic Braking system is of two types,

1. Front/Rear Split

2. Diagonal Split

Hydraulic Braking system incorporated with ABS (Antilock Braking System) is controlled by ECU by hydraulic moderator unit.

\subsection{Disc and Drum Brakes}

In Disc brakes, caliper with linings is used to create friction whereas in drum brakes, brake shoes are used to create friction. In both disc and drum brake the movement of lining and brake shoe is actuated by a brake fluid. Types of Incompressible brake fluids are,
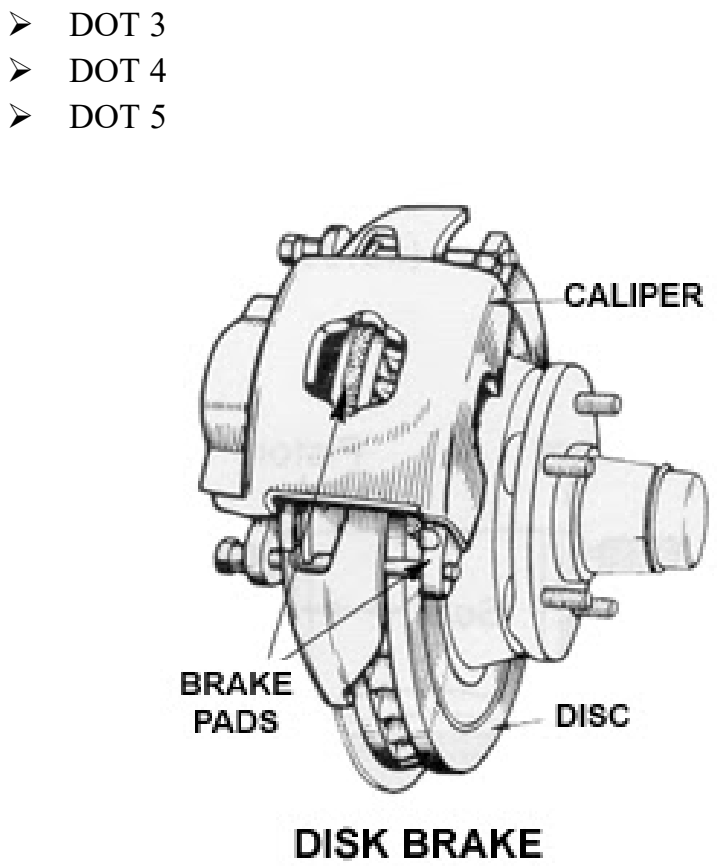

Fig 5. Parts of Disc Brakes

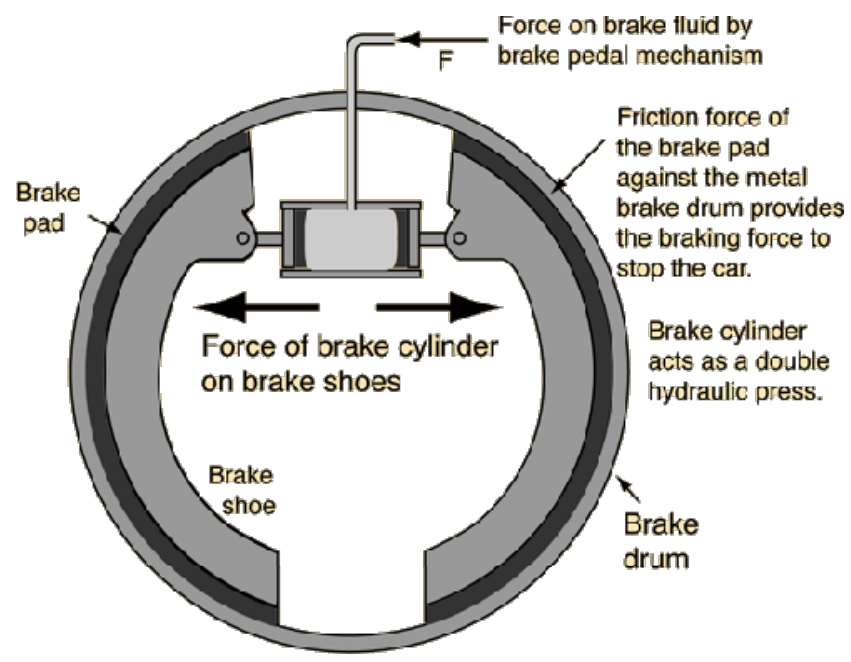

Fig 6. Working of Drum brakes 


\section{FUEL INJECTORS}

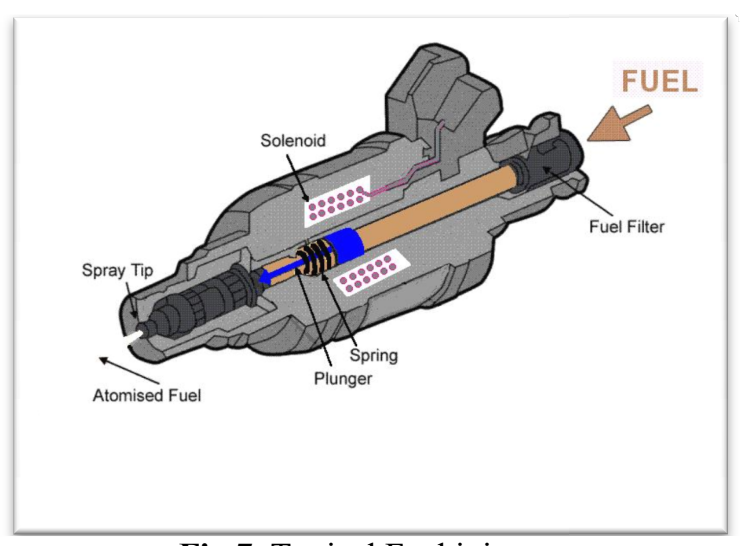

Fig 7. Typical Fuel injector

Fuel Injectors are the system that is used to inject the fuel into the Internal Combustion Engine. The quantity of fuel injected by this system is controlled by ECU. Fuel Injectors are most often used in diesel Engines, nowadays fuel injector is used as a replacement of Carburetor. The quantity of fuel injected is directly responsible for the power output.

\section{WORKING OF GPBS}

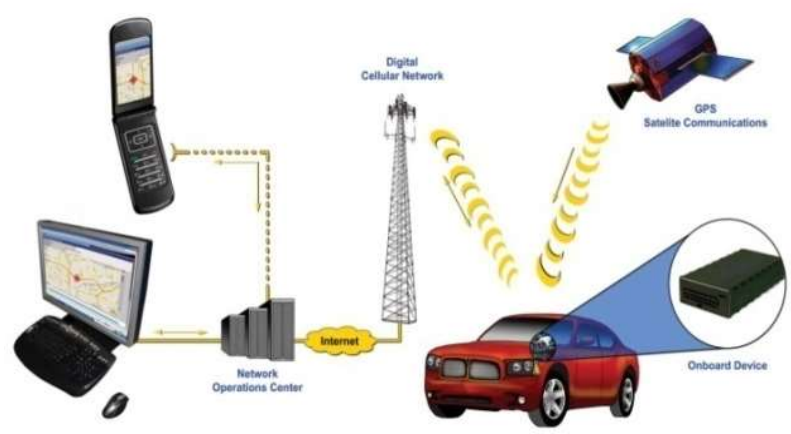

Fig 8. Global positioning of vehicle with help of satellite

\subsection{Position and Steep Tracking}

The Position and Steep at which vehicle travelling is tracked with the help of onboard devices. This onboard device consists of a Positioning chip and clinometers. The positioning chip receives signal from satellite and transmits it back to satellite. By this process, the location of vehicle is exactly known. On the other hand, Clinometers fixed in onboard device measures the steep angle with the help of self-adjusting spirit level. All these data is fetched by GPBS. When a computer or a phone is connected to the corresponding satellite, the position and steep angle can be known.

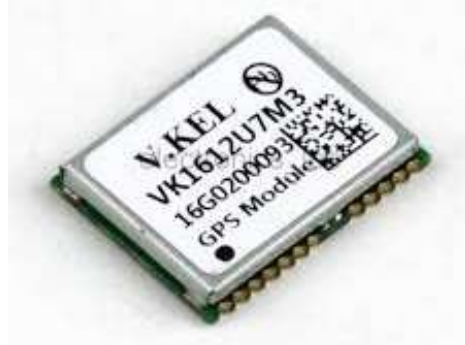

Fig 9. Positioning chip

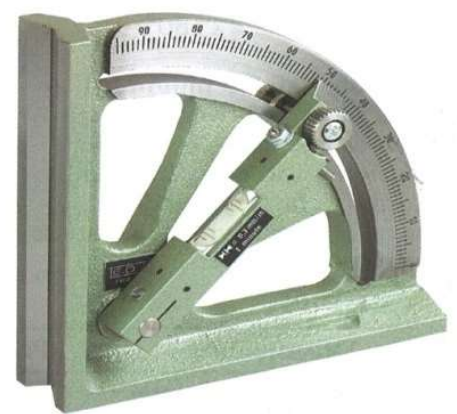

Fig 10. Convectional Clinometers

\subsection{Processing Data at ECU}

The data received from onboard device is transmitted to Electronic Control Unit. Based on the data and presetprogram, ECU actuates the Hydraulic moderator unit and Fuel injector to control Brakes and Fuel supply respectively. By this actuation the brakes are applied automatically and fuel is cut-down to required rate when vehicle over speeds.

\section{Preferred Conditions}

\section{Junction}

If a Vehicle is travelling in a highway at a speed of $90 \mathrm{kmph}$ and is approaching a junction ahead where the speed limit is $60 \mathrm{kmph}$, by this time the position of vehicle is tracked by Positioning chip and data is sent to ECU. This data is processed by ECU and actuates the braking system and fuel injector before $200 \mathrm{mts}$ of junction and gradually cuts down the speed to $60 \mathrm{kmph}$ automatically.

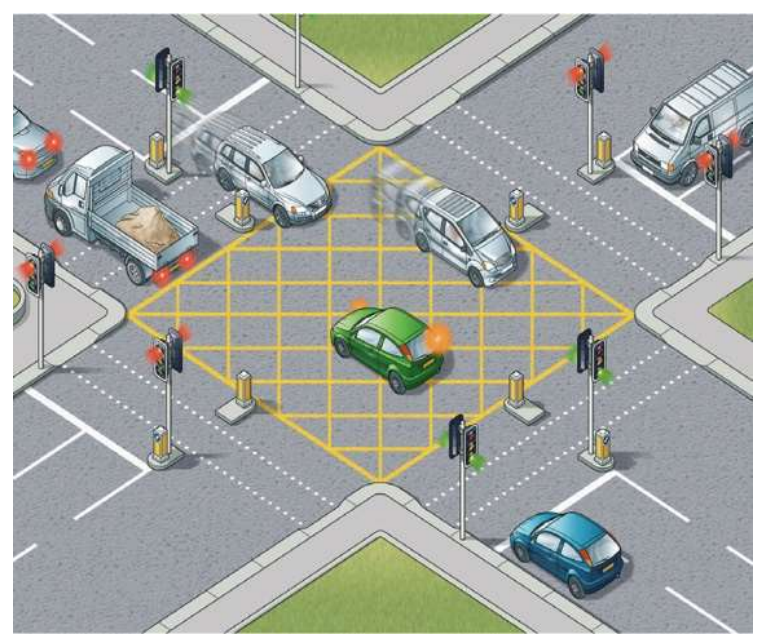

Fig 11. Junction descriptions in road

\section{UP-HILL}

If a Vehicle is climbing a hill, it requires more power. The steep at which the vehicle is tracked by variation in spirit level of clinometers in onboard device and this data is sent to ECU. If the vehicle is towards steep greater than $25 \mathrm{deg}$, ECU disables the preset program and doesn't actuate the braking and fuel injection system. Thus the Vehicle climbs up freely as per acceleration given. 


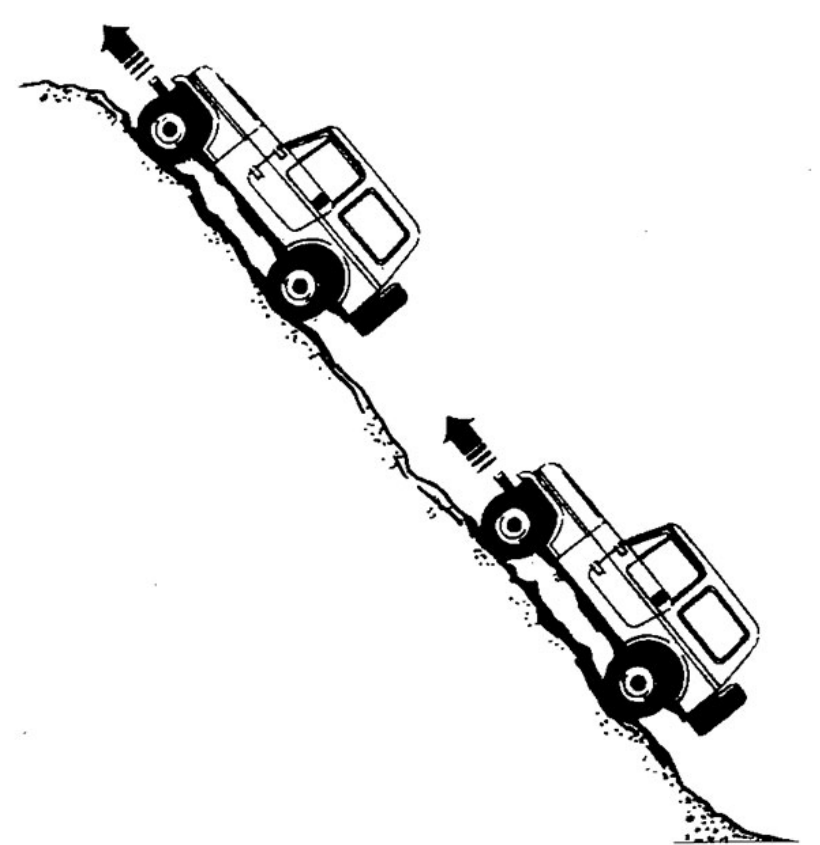

Fig 12. Vehicle in Up-hill

\section{DOWN-HILL}

When a vehicle is approaching slope (or) Down-hill, that data of steep is fetched by ECU with help of onboard devices and based on the preset program speed limit, Fuel supply is controlled by ECU. The Braking system is actuated when necessary.

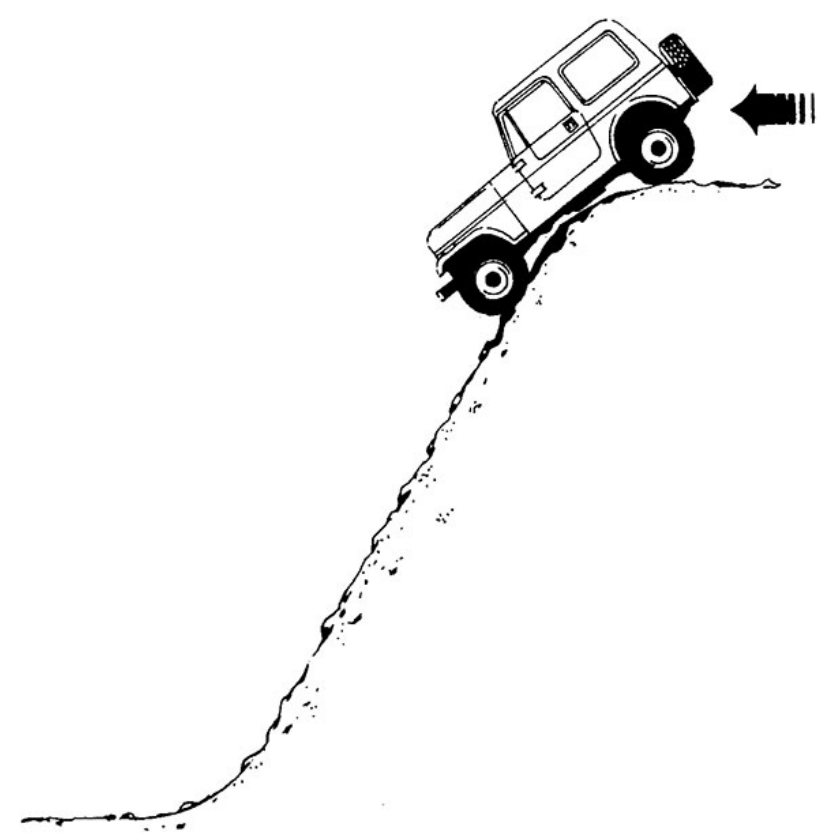

Fig 13. Vehicle in Down-hill

\section{City Limit}

When the vehicle is within city limit, where the speed is limited, the position of vehicle is fetched by ECU which actuates Braking system and Fuel injector to maintain the speed limit within the city. This City limit actuation is done like a loop whenever vehicle crosses the speed limit of city.

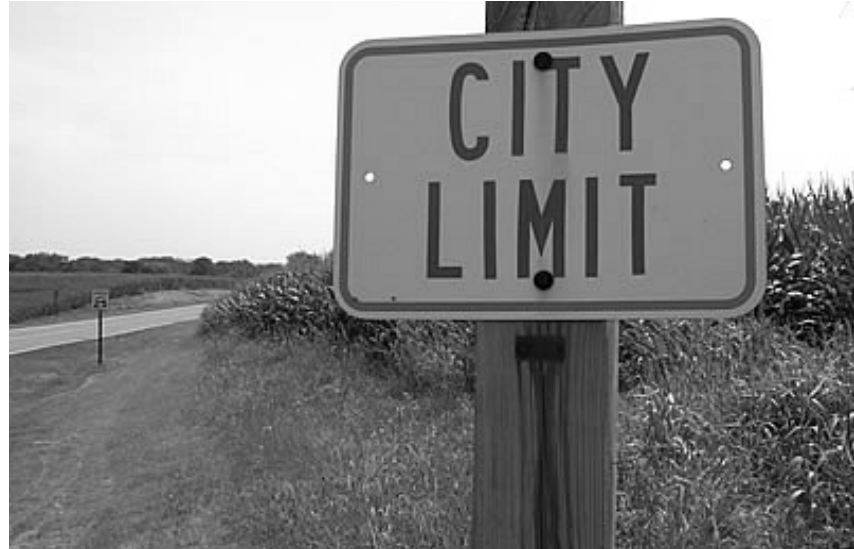

Fig 14. Sign board describing city limit

\section{ADVANTAGES OF GPBS}

1) Number of accidents is greatly reduced.

2) Ensures the safety of Passengers.

3) Driver gets better control in Down-hill condition.

4) Simple to program and easy to construct.

5) Can be used for fleet location too.

6) Could be installed in all vehicles.

7) Easy tracking of theft vehicles.

8) Steer ability even under braking.

\section{DISADVANTAGES OF GPBS}

1) Totally based on satellite connection.

2) Difficult to program for certain situations.

3) Error in program might lead to poor performance.

4) Speed limit is applied irrespective of traffic.

\section{CONCLUSION}

In this current era, the percentage of road accidents and fatality rate keeps on increasing. Thus GPBS be the effective technology to reduce those issues. GPBS ensures road safety in driverless cars too.

\section{REFERENCES}

[1]. Government of India, Ministry of Road transport and Highway transport research wing 2016 publication.

[2]. https://www.Sites.ndtv.com/roadsafety/importantfeature-to-you-in-your-car-5/

[3]. The Hindu, Article-8469478.

[4].https://countryliving4beginners. wordpress.com/2015/05/ 02/the-discombobulated-ditzs-downhill-dilemma/

[5]. https://www.howacarworks.com/basics/how-thebraking-system-works

[6].www.sae.org/students/presentations/brakes_by_paul_s_g ritt.pdf 


\section{BIOGRAPHIES}

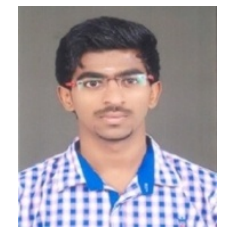

Vivek M., 19. Graduated from Sri Sowdeswari Vidyalaya Matriculation Higher Secondary School. He is pursuing his Bachelor of Engineering under the discipline Mechanical. As a member of SAE, he actively participated in Efficycle2015 event. He proved his driving skills in Dirt bike events.

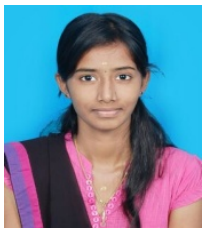

Srisumanithi P., 19, Graduated from Velammal Matriculation Higher Secondary School with Secondary School Leaving Certificate. She is pursuing her Bachelor of Engineering under the discipline Mechanical. She is a member of SAE. She actively participated in Aero-modeling Event. She proved her skill by fabricating a Wooden Lathe.

[Submission for: International Journal of Research in Engineering and Technology, Vol-06 Iss-01,Jan 2017] 